\title{
Monitoramento e avaliação em perspectiva democrática
}

Monitoring and evaluation in democratic perspective

Luis Satie $^{1}$

RESUMO: Após a Constituição de 1988, a metodologia de monitoramento e avaliação das políticas públicas deve incorporar a participação da sociedade civil. Este artigo, após revisão seletiva da literatura, sob o enfoque do direito político, sugere um modelo dialógico para o controle democrático das ações do Estado, inspirado em experiência recente do governo federal na área do meio ambiente.

PALAVRAS-CHAVE: Políticas públicas - Monitoramento - Democracia.

ABSTRACT: After the 1988 Constitution, the methodology of monitoring and evaluation of public policies should incorporate the participation of civil society. This article, after selective review of the literature, from the standpoint of the political right, suggests a dialogical model for the democratic control of government actions, inspired by recent experience of the federal government in the area of environment.

KEYWORDS: Public policies - Monitoring - Democracy.

\section{Considerações Iniciais}

O nosso (velho) direito administrativo é produto de dois extratos históricos. De um lado, como originário da Revolução Francesa, assumiu um aspecto autoritário e hierárquico, pautado no controle de procedimentos; de outro, como ressonância do direito português, absorveu a ideia de unidade estatal. Como consequência, a ordem administrativa brasileira elegeu a supremacia do interesse público como princípio unilateral, voltado para a afirmação enfática do Estado e da lei e fundado na filosofia da consciência, no consenso e na verdade única. Essa ordem administrativa autoritária, vigente, impede que o Brasil se torne uma associação política, aberta ao controle popular e ao uso público de uma razão dialógica e autônoma, sem o que não seria possível a construção de uma sociedade livre, justa e solidária.

A Constituição Federal de 1988, fundada na afirmação normativa da dignidade, do pluralismo e dos direitos fundamentais exige a superação do princípio da autoridade, que tem regido o direito administrativo do Estado brasileiro e, por

Pós-doutor em Filosofia Política Normativa e Doutor em Filosofia e Ciências Sociais (EHESS - Paris), Mestre em Filosofia e Teoria do Direito (UFSC). Pesquisador do Grupo Neokantismo e Filosofia Contemporânea do CNPq/UFPB. Endereço: Rua Raul Pompeia, 141/803. CEP 22080-000. Rio de Janeiro-RJ.

(21) 7563.8922. e-mail: luis.satie@alumni-ehess.fr.

REVISTA DO DIREITO UNISC, SANTA CRUZ DO SUL

№ 41|p. 89 - 109|NOV - DEZ 2013 
conseguinte, a relação Estado-sociedade. Segundo Canotilho (1992), o direito à prestação social do estado é um direito fundamental inafastável do direito à participação popular direta nas organizações estatais, por meio de procedimentos transparentes. No entanto, em suas palavras: "Os cidadãos permanecem afastados das organizações e dos processos de decisão, dos quais depende afinal a realização dos seus direitos" (Canotilho, 1992, p. 543). Por essa razão, nosso Estatuto Maior, promulgado em 05 de outubro de 1988, expressa uma decisão política fundamental em nossa história constitucional: o povo deve exercer diretamente o poder, ou indiretamente, por meio de seus representantes, eleitos conforme as regras do jogo democrático. A partir dessa decisão política, todas as instituições estatais são instadas a abrir-se a participação popular, a partilhar o ato de legislar, governar e julgar com a sociedade civil. Nessa partilha deve incluir-se o poder de gerir, monitorar e avaliar as políticas públicas.

\section{O direito fundamental à democracia}

A administração pública brasileira carece de reformulação para se adequar à concepção de Estado definida na Carta de 1988. Esse apelo tem repercutido na literatura especializada mais recente. Como ressalta um dos juristas atentos a essa demanda prática:

(...) no contexto de um Estado Democrático de Direito (CF, art. $1^{\circ}$, caput), direitos fundamentais e democracia se apresentam como os principais elementos estruturantes das instituições jurídicas e estatais, aí incluídas as estruturas administrativas. Tal postura deve desencadear - e já vem desencadeando - um processo de transformação na administração pública brasileira e na cultura administrativa pátria, alicerçadas em grande parte num paradigma jurídico-administrativo "burocrático", "autoritário" e tradicionalmente apartado dos valores e princípios constitucionais. (...) Tal modelo jurídicoadministrativo, contudo, começa a ceder lugar a um paradigma pós-burocrático, de caráter mais ético, menos positivista e 
menos formalista, centrado na efetivação de direito fundamentais (Pessoa, 2006, p. 43).

Inclua-se nesse programa o próprio direito fundamental à democracia, ou seja, o direito ao exercício partilhado do poder político. Nessa medida, não é razoável o insulamento da administração pública em face dos outros poderes e da sociedade civil. O Estado Democrático de Direito demanda uma gestão pública democrática e eficiente, comprometida com a concretização dos direitos fundamentais postos, explícita ou implicitamente, na Constituição Federal.

Não obstante, o espectro autoritário da velha ordem administrativa, herança do antigo regime, sobreviveu intacto, da monarquia à república, passando pelo Estado unitário, federativo, liberal, social e neoliberal, bem como por seus modelos de administração patrimonialista, burocrática e gerencial, a ponto de entravar o ainda lento processo de democratização das políticas sociais. Nascidas no Estadoprovidência, tais políticas, bem como seus modelos de análise, não se coadunam facilmente com a nova demanda constitucional, com acento na partilha do poder democrático.

De fato, se dermos uma olhada na literatura existente não teremos facilidade de encontrar uma abordagem com essa vocação, pois a ideia de política pública é impregnada da missão de impulsionar o desenvolvimento econômico e promover a inclusão social (Souza, 2006, p. 21). Além de ter esse apelo distributivista, a ideia de política pública tem forte acento centralizador, desde suas origens. Autores europeus e americanos tem sempre partido do pressuposto de que os governos são os protagonistas por excelência da implementação das políticas públicas (Souza, 2006, p. 22).

Com efeito, Laswell (1936) introduziu a expressão policy analysis para referirse ao estudo da ação dos governos. Simon (1957) introduziu o conceito de racionalidade limitada dos decisores públicos (policy makers), voltada à maximização de regras e estruturas do Estado com o fim de moldar o comportamento dos atores de acordo com os fins definidos pela burocracia.

Talvez, a primeira tentativa de trazer elementos exógenos aos aparelhos de Estado à análise das políticas públicas tenha sido a de Lindblom (1959; 1979), por incorporar a esse conjunto teórico o papel das eleições, das burocracias, dos 
partidos e dos grupos de interesse na formulação e implementação de tais políticas. Easton (1965) trouxe ao conceito de políticas públicas a ideia de sistema, com abertura para a sociedade civil, ambiente de onde tais políticas poderiam receber inputs dos partidos, da mídia e dos grupos de interesse, a fim de influenciar seus resultados e efeitos (output).

Esse caráter distributivista-centralizador também está presente na concepção mais recente de políticas públicas. Mead (1995), por exemplo, põe ênfase no estudo do governo à luz de grandes questões públicas. Lynn (1980) destaca em sua abordagem um conjunto de ações do governo que irão produzir efeitos específicos. Para Peters (1986), a política pública é a soma das atividades dos governos, que agem diretamente ou através de delegação, e que influenciam a vida dos cidadãos. Vemos em Dye (1984) a ideia de política pública como "o que o governo escolhe fazer ou não fazer".

Não tem sido diferente a abordagem jurídica do tema. Tomemos a seguinte definição de políticas públicas, modulada por elementos normativos, já no quadro da nossa Constituição Federal:

(...) conjuntos de programas de ação governamentais estáveis no tempo, racionalmente moldadas, implantadas e avaliadas, dirigidas à realização de direitos e redistribuição de bens e posições que concretizem oportunidades para cada pessoa viver com dignidade e exercer seus direitos, assegurando-Ihes recursos e condições para a ação, assim como a liberdade de escolha para fazerem uso desses direitos (Massa-Arzabe, 2006, p. 72).

Vemos aqui mais uma vez a permanência da ideia distributivista e centralizadora presente na literatura mais clássica. Do conceito acima depreende-se, em primeiro lugar, que uma política pública é originária dos governos (aspecto centralizador). Em segundo lugar, deve ser marcada pela ideia de especificidade e carência. Ou seja, deve ser dirigida a públicos específicos, atingidos pelas consequências da desigualdade social, para que não degenere em política para as elites ou para quem não precise dela (aspecto distributivo). Não obstante, mesmo nessa definição mais atual, temos o esquecimento da componente democrática, a 
saber, a participação popular na concepção, implementação e avaliação de ações compartilhadas entre agentes públicos estatais e não estatais.

Se quisermos ser fiéis ao modelo de Estado que escolhemos para o Brasil, devemos incorporar ao caráter centralista e distribuidor de nossas políticas públicas o componente propriamente democrático. Por isso, os programas de governo, porque financiados pelo orçamento público no ambiente de um Estado Democrático de Direito, deveriam ser voltados para a capacitação e sensibilização popular. Tais programas são prestações sociais do Estado; ou seja, se constituem como políticas públicas, que, como tais, deveriam ser voltadas para os que têm dificuldade de acesso aos bens públicos. Entretanto, esse público-alvo não deve continuar excluído do exercício comunitário do poder de participar e de deliberar, razão pela qual, para evitar que os objetivos dessa aproximação entre Estado e sociedade sejam desvirtuados, é necessário um plano de monitoramento transparente, aberto, democrático e participativo.

Certo, em nossa ordem constitucional, as políticas públicas devem apontar para a realização dos objetivos do art. $3^{\circ}$ de nossa Carta Maior, a saber, I. Construir uma sociedade livre, justa e solidária; II. Garantir o desenvolvimento nacional; III. Erradicar a pobreza e a marginalização e reduzir as desigualdades regionais e IV. Promover o bem de todos. Entretanto, tais políticas não podem existir sem o monitoramento e avaliação da sociedade civil, para que não degenerem em propaganda e manipulação de dados e planilhas.

Assim, para que cada centavo do Tesouro seja aplicado para a realização desses objetivos, sem desperdício ou desvio, é preciso que os programas do governo sejam monitorados, com regras claras, definidas com os grupos de interesses sociais, de modo imparcial, a fim de: 1. garantir a eficiência; 2. guiar, revisar e ajustar a estratégia; 3. possibilitar a transparência na informação; 4. fortalecer a comunicação e 5. atingir um público-alvo carente e específico, convidando-o a ser co-sujeito da governança social. Fazer política pública não pode continuar sendo tarefa unidirecional de uma comunidade de especialistas, os policy makers dos governos, cujas planilhas podem favorecer mais facilmente determinado grupo de interesses, em detrimento do público mais legitimado pela situação social. O diálogo entre especialistas e público-alvo seria a melhor maneira de evitar que - 
conforme a pertinente preocupação de Olson (1965) - as decisões inspiradas em interesses comuns carreassem a apropriação de resultados para a esfera particular de grupos (free riding) já beneficiados por sua posição no sistema de distribuição de bens de vida.

Por esse viés, o sistema de políticas públicas deixaria de ter uma natureza meramente instrumental para adquirir uma natureza substantiva, catalisadora da própria ressignificação da política como um todo, a partir da emergência do protagonismo do povo soberano nos negócios do Estado. Em suma, como tecnologia de partilha do poder político, as políticas públicas, além de democráticas, seriam republicanas. Nesse sentido, o sistema de políticas públicas não seria uma extensão do modelo de política vigente, mas sua superação. Por assim dizer: a política pública não faz a política, como quer Lowi (1964; 1972), mas se põe como condição de possibilidade de sua sauvetage do sistema de partidos políticos e do sistema das corporatocracias, indutores de paradigmas da economia política mundial e vetores de colonização do interesse público pela racionalidade utilitarista dos mercados.

Prescrutemos abaixo, a partir da metodologia utilizada recentemente pelo Ministério do Meio Ambiente em projetos de desenvolvimento sustentável (Valarelli, 2005; Ascher e Valarelli, 2008), o modelo de controle de políticas públicas que pode contribuir para colmatar a lacuna que impede o diálogo entre especialistas (policy makers) e público-destinatário das políticas fundamentais impressas no art. 3ํ de nossa Constituição Federal, de modo a fortalecer o princípio da soberania popular estatuído em seu art. 1ํㅡㄹ parágrafo único, não só na área ambiental, mas em todas as outras esferas de atuação do Estado.

\section{MÉTODOS DE MONITORAMENTO E AVALIAÇÃO}

Segundo Ascher e Valarelli, existem três tipos de monitoramento: o financeiro, o de desempenho e o de impactos. O primeiro compara o planejamento com a execução dos recursos; o segundo compara o que foi feito com o que foi programado e o terceiro afere o que mudou na sociedade, "enfoca os objetivos, os benefícios obtidos e as mudanças que aconteceram como consequência da 
implementação do projeto. (...) traz informações que permitem a reflexão, a análise, o questionamento e o ajuste das estratégias iniciais adotadas" (Ascher e Valarelli, 2008, p. 20).

Estamos num momento de transição do Estado de Direito para o Estado Democrático de Direito, em que o princípio da soberania popular deve concretizar-se como exercício compartilhado do poder político entre o Estado e a sociedade civil. Essa transição constitucional encarna um espírito pedagógico de transformação de uma cidadania passiva em cidadania ativa, que deverá se traduzir no controle social cada vez mais amplo e crítico das ações do Estado administrativo. Por essa razão, julgamos que o monitoramento de impactos é mais pertinente para que se acompanhe essa mudança de paradigma constitucional, sendo o monitoramento financeiro e o de desempenho meios para o alcance dos fins estatuídos pela assembleia constituinte, em decisão fundamental e programática.

Como monitoramento de fins, a pergunta-chave que agentes do Estado e da sociedade civil devem fazer a respeito de cada política pública implementada não é: o que foi feito? Mas: com o que foi feito, foram alcançados os objetivos previstos? Para melhor interrogar essas ações planejadas de condução de um modelo constitucional negativo para um modelo positivo de exercício das liberdades públicas, o monitoramento de impactos pode ser realizado a partir de três abordagens: 1. A abordagem lógica; 2. A abordagem da gestão participativa de impactos e 3. A abordagem negocial. Vejamos abaixo cada uma delas, para que possamos identificar suas vantagens e desvantagens e definir, por conseguinte, o tipo mais adequado para que as políticas sociais sejam uma oportunidade não só de distribuição de bens, mas de distribuição equitativa do poder político.

\subsection{A abordagem lógica}

Esse método (Vide Valarelli, 2005, p. 26-33) detalha os objetivos, as atividades e os resultados de um programa ou projeto, acentuando as relações de causalidade implicadas, de modo a compor uma matriz de análise, como nos quadros 1 e 2 abaixo:

\section{Quadro 1}




\begin{tabular}{|l|l|l|}
\hline $\begin{array}{l}\text { Estratégia do } \\
\text { Programa }\end{array}$ & $\begin{array}{l}\text { Indicadores objetivamente } \\
\text { verificáveis }\end{array}$ & $\begin{array}{l}\text { Fontes de } \\
\text { verificação }\end{array}$ \\
\hline Objetivo geral & & \\
\hline Objetivos específicos & & \\
\hline Resultados & & \\
\hline
\end{tabular}

\begin{tabular}{|l|l|l|}
\hline \multicolumn{3}{|c|}{ Quadro 2 } \\
\hline Abordagem lógica \\
\hline Atividades & Meios & Custos \\
\hline & & \\
\hline
\end{tabular}

Por essa abordagem, o programa ou projeto pode ser monitorado por duas lógicas articuladas, uma vertical e outra horizontal. Na primeira coluna da matriz lógica temos a cadeia de impacto do programa, que se irradia de baixo para cima: das atividades que geram resultados e que, por conseguinte, realizam objetivos específicos para alcance do objetivo geral. Na segunda e terceira colunas são apresentados os indicadores que permitem o acompanhamento objetivo do programa, com aferição do grau de consecução dos objetivos propostos.

Os indicadores no nível de objetivo geral são, propriamente, os indicadores de impacto, que apontam concretamente se o programa está exercendo alguma influência no meio social. Os indicadores no nível dos objetivos específicos são os indicadores de impacto direto, no sentido de fornecerem pistas seguras de que seu público-alvo esteja mudando de comportamento. Os indicadores de nível de resultados são os indicadores de desempenho do programa, pois aferem a quantidade, qualidade e prazo de realização dos produtos e serviços previstos, além de indicar as características do público atingido, informando se este está ou não em consonância com o público-alvo escolhido.

Qual a vantagem dessa abordagem para o desenho de monitoramento de um programa ou projeto? De uma parte, esse método de monitoramento promove a 
compreensão objetiva da estratégia de intervenção do programa, evitando a manipulação dos dados ou o não partilhamento dos resultados com a sociedade civil, pois permite que esta identifique com detalhes os campos de incidência e as metas do programa. De outra parte, permite que atores, espectadores e parceiros do programa possam acompanhá-lo de modo concomitante, criando condições objetivas para um diálogo entre sociedade e Estado, por meios de indicadores claros e mensuráveis.

\subsection{A gestão participativa de impactos}

Nessa abordagem, os gestores podem encetar os seguintes passos metodológicos, a fim de reinaugurar o programa a partir de um marco zero de discussão pública, de exercício da razão comunicativa ou argumentativa, no sentido apresentado pela filosofia social de Habermas (1984; 1997).

\section{a) Existência de condições prévias}

Os gestores devem responder às seguintes questões, antes de colocar em cena a gestão participativa de impactos (GPI): 1. desejam experimentar novo conceito de monitoramento? 2. dispõem-se a usar o tempo necessário para o monitoramento e tomada de decisões coletivas? 3. aceitam possíveis perdas de influência ou partilha de poder? 4. desejam maior transparência em suas ações? 5. dispõem-se a superar conflitos e divergências entre atitudes, expectativas e objetivos dos diversos atores envolvidos na GPI?

\section{b) Conhecimento do contexto}

Reconhecida a existência dessas condições prévias, os gestores, ainda antes da introdução do GPI, devem sistematizar todas as informações do programa referentes ao seu método de trabalho, sua gênese e desenvolvimento e características das parcerias envolvidas -, e compartilhá-las, de modo participativo e democrático, com os integrantes do processo de monitoramento.

\section{c) $O$ que deve ser observado?}

É então que a GPI tem seu início com o levantamento das expectativas e 
receios relativos às mudanças geradas pelo programa, bem como com a seleção das mudanças consideradas relevantes para o grupo constituído por membros do governo e da sociedade civil organizada.

\section{d) Como observar?}

Para cada expectativa ou receio são definidos indicadores, fontes de informação e o método de observação, com priorização das informações obtidas pelos próprios membros do grupo da GPI, por serem mais confiáveis, geradoras de discussão interna e menos dispendiosas.

\section{e) Quem deve observar?}

Nesse passo, são definidos democraticamente quem vai a campo coletar as informações necessárias para a análise.

\section{f) Como registrar as informações?}

Antes da ida a campo, o grupo define as regras para anotação, documentação e registro das informações, bem como as regras de compartilhamento das mesmas, por meio de sua inserção num circuito de transparência, cujos pilares são: quais informações, para quem, quando e como?

\section{g) $O$ que foi observado?}

É o momento da partilha, da apresentação e socialização das informações entre os membros do grupo.

\section{h) Por que foram obtidos esses resultados?}

Nesse passo os resultados obtidos são analisados e discutidos, de acordo com as expectativas do programa. É o momento de identificar as relações de causaefeito e influências das atividades do programa, se positivas ou negativas ou mesmo inesperadas.

\section{i) Que ação deve ser realizada?}

Finalmente, a partir das análises e aprendizados colhidos, tomam-se 
decisões, aperfeiçoa-se o sistema de monitoramento, ajustam-se indicadores, melhoram-se os processos de observação e comunicação, replaneja-se o programa e redefinem-se as atividades.

\section{j) Vantagens}

Essa abordagem participativa tem a vantagem de politizar o monitoramento, dividir responsabilidades e poderes, gerar informações que atendam às expectativas dos membros do grupo de monitoramento, formado por membros do Estado e da sociedade civil organizada. A GPI é adaptável a qualquer programa de baixa complexidade, perfeitamente manejável pelos recursos existentes. Além disso, possibilita o aprendizado, é de fácil implementação e favorece o uso da razão democrática.

\subsection{A abordagem negocial}

Reunindo as vantagens da abordagem lógica e da gestão participativa de impactos, Ascher e Valarelli sugerem a abordagem negocial como a mais completa, uma vez que reúne o aspecto formal de acompanhamento lógico da cadeia de impactos com o aspecto mais democrático da gestão do monitoramento. Toda política pública deve ter como missão justamente disseminar a prática do controle social e se por como o exemplo mais palpável (experimenta crucis) do tipo ideal pedagógico exigido para que a era neoconstitucionalista seja modulada por tecnologias de devolução do poder político à sociedade. Essa missão exige uma maior estruturação das políticas sociais, bem como a assunção da responsabilidade de montar um sistema de monitoramento transparente. Nesse sentido, consideramos bastante pertinente a abordagem negocial, enquanto abordagem-síntese para esse momento de transição constitucional, que poderá propulsionar a mudança do paradigma burocrático de organização do Estado, herança autoritária do Estado social.

Não obstante, dada a estrutura extremamente verticalizada e centralizada de nosso modelo de administração pública, pode-se inferir que a aplicação desse mecanismo de monitoramento confrontar-se-ia com o paradigma burocrático adotado, pouco aberto ao exercício da gestão participativa com outros atores e 
setores da sociedade civil.

Para superar esse quadro, apontamos cinco momentos de mudança de qualidade na gestão das ações de governo, de modo a conduzi-la ao estágio da nova administração pública, fundada na nova ordem constitucional que, como vimos, adotou para o Brasil o conceito de democracia participativa, inscrito no princípio da soberania popular, anunciado no art. 1ํ de nossa Constituição: 1. Mapeamento dos impactos na cadeia de impactos; 2. Mapeamento dos atores e seus interesses/questões e definição conjunta dos âmbitos de impacto mais relevantes; 3. Negociação e priorização dos âmbitos de impactos mais relevantes; 4. Estratégia de monitoramento: o desenho dos momentos, procedimentos e atores envolvidos no monitoramento dos impactos priorizados; 5. Operacionalização dos instrumentos e planejamento das ações de monitoramento.

\section{a) Momento 1: mapeamento dos impactos}

Esse mapeamento não se restringe ao desenho da cadeia de impactos em torno dos objetivos gerais e específicos, como seria o caso na abordagem lógica. Aqui todos os impactos possíveis, diretos ou indiretos, devem ser previstos por cada linha de ação ou componente do programa. O mapa pode ser configurado a partir dos insumos apresentados nos quadros 3,4 e 5 :

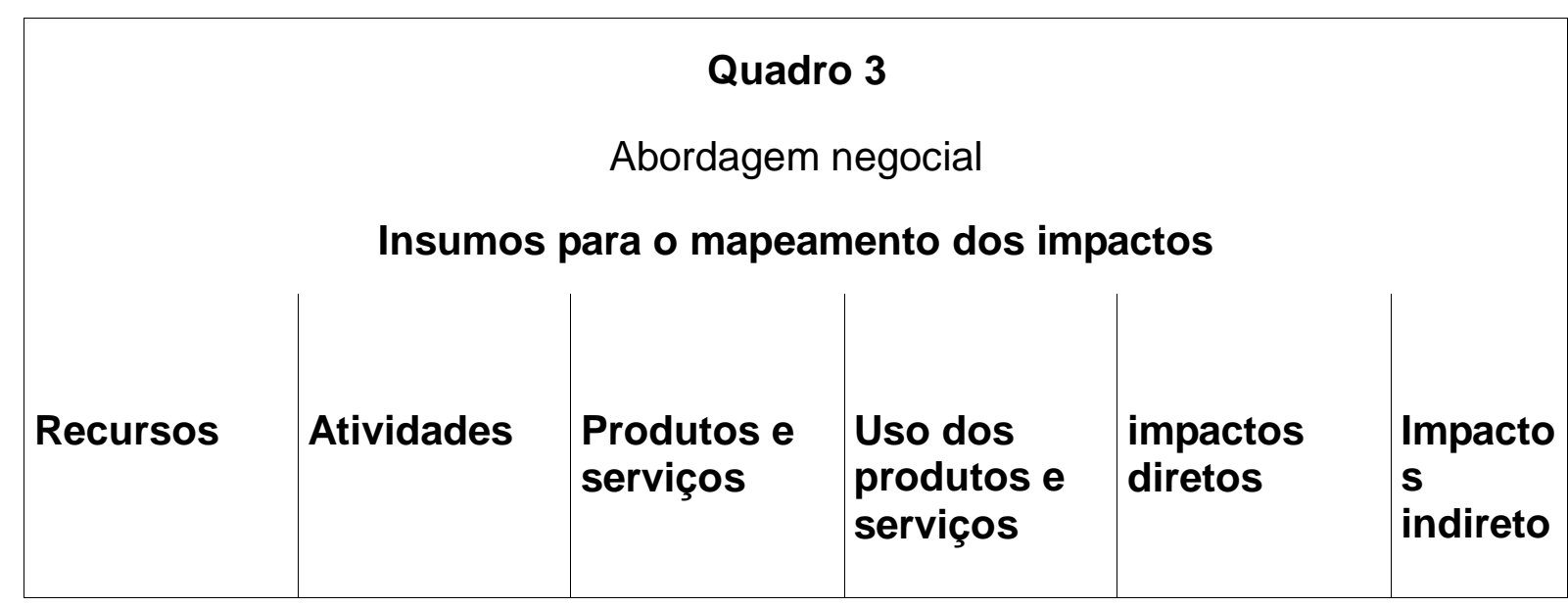






\begin{tabular}{|l|l|}
\hline \multicolumn{1}{|c|}{$\begin{array}{c}\text { Quadro 4 } \\
\text { Abordagem negocial } \\
\text { Momento 1: mapeamento dos impactos }\end{array}$} \\
\hline Humanos & $\begin{array}{l}\text { Indicar a quantidade, formação e perfil } \\
\text { dos servidores disponibilizados para o } \\
\text { programa. }\end{array}$ \\
\hline Operacionais & Descrever a estrutura de trabalho \\
\hline Orçamentários & Indicar as fontes orçamentárias \\
\hline
\end{tabular}

\begin{tabular}{|l|l|l|l|l|l|}
\hline \multicolumn{5}{|c|}{ Quadro 5 } \\
Abordagem negocial \\
Momento 1: mapeamento dos impactos \\
\hline $\begin{array}{l}\text { Linhas } \\
\text { de ação }\end{array}$ & Atividades & Produtos & $\begin{array}{l}\text { Uso dos } \\
\text { produtos }\end{array}$ & $\begin{array}{l}\text { Impactos } \\
\text { diretos }\end{array}$ & $\begin{array}{l}\text { Impactos } \\
\text { indiretos }\end{array}$ \\
\hline & & & & & \\
\hline
\end{tabular}

b) Momento 2: mapeamento dos atores e seus interesses e questões

Nessa etapa devem ser mapeados todo o campo de força subjetivo do programa, seus atores, interesses e expectativas, para que o programa seja de fato compartilhado intersubjetivamente e seus resultados não se afastem do que cada 
ator espera. De fato, mapeia-se aqui o próprio pacto estabelecido, para que se tenha claro a direção que o programa está tomando e para que o programa não degenere em mero diálogo de surdos entre os atores interessados. O quadro 6 mapeia os principais atores, características, preocupações e interesses envolvidos na ação governamental:

\begin{tabular}{|l|l|l|l|}
\hline \multicolumn{3}{|c|}{$\begin{array}{c}\text { Quadro 6 } \\
\text { Abordagem negocial }\end{array}$} \\
\hline Grupos e atores & Características & $\begin{array}{l}\text { Preocupações e } \\
\text { interesses em } \\
\text { relação ao } \\
\text { programa }\end{array}$ & $\begin{array}{l}\text { Qualidade da } \\
\text { relação com o } \\
\text { programa }\end{array}$ \\
\hline & & \\
\hline
\end{tabular}

c) Momento 3: negociação e priorização dos impactos mais relevantes

Nesse estágio, de posse do conjunto-universo dos impactos e atores, é preciso negociar acerca dos pontos de incidência do programa mais importantes, bem como sobre os interesses que devem ser contemplados no monitoramento e avaliação. É, sem dúvida, o momento da razão argumentativa, em que a hierarquia do órgão deve ceder à horizontalidade exigida por nosso Estado Democrático de Direito, ainda mais em se tratando de um programa voltado a fomentar o controle social. Os policy makers podem adotar os seguintes passos, sistematizados no quadro 7: 1. Identificar os atores mais importantes para os objetivos do programa; 2. Identificar as áreas de maior interesse desses atores; 3. Identificar as áreas sensíveis que podem comprometer o êxito do programa (Ascher e Valarelli, 2008, p. $55)$.

\begin{tabular}{|l|l|l|l|}
\hline \multicolumn{3}{|c|}{$\begin{array}{c}\text { Quadro 7 } \\
\text { Abordagem negocial }\end{array}$} \\
\hline \multicolumn{2}{|c|}{ Momento 3: negociação e priorização dos impactos mais relevantes } \\
\hline $\begin{array}{l}\text { Grupos e } \\
\text { atores }\end{array}$ & $\begin{array}{l}\text { Preocupações e } \\
\text { interesses mais }\end{array}$ & Impactos diretos & Impactos indiretos \\
\hline
\end{tabular}




\begin{tabular}{|l|l|l|l|}
$\begin{array}{l}\text { estratégic } \\
\text { os }\end{array}$ & relevantes & prioritários & \\
\hline & & & \\
\hline & & & \\
\hline
\end{tabular}

\section{d) Momento 4: desenho da estratégia de monitoramento}

É nessa etapa que o modus operandi do monitoramento é definido. Para cada impacto priorizado, é preciso 1. indicar os momentos e a periodicidade em que serão monitorados e avaliados; 2 . indicar os envolvidos e sua forma de participação no processo de monitoramento e 3 . indicar as atividades e procedimentos que constituirão propriamente o processo de monitoramento e avaliação. Essa estratégia de monitoramento pode ser melhor visualizada no quadro 8 :

\begin{tabular}{|l|l|l|l|}
\hline \multicolumn{4}{|c|}{$\begin{array}{c}\text { Quadro 8 } \\
\text { Momento 4: } \\
\text { desenho da estratégia de monitoramento }\end{array}$} \\
\hline Impactos diretos & $\begin{array}{l}\text { Momentos } \\
\text { e } \\
\text { periodicida } \\
\text { de }\end{array}$ & $\begin{array}{l}\text { Envolvidos } \\
\text { Atividades } \\
\text { e procedimentos }\end{array}$ & \\
\hline Impactos indiretos & $\begin{array}{l}\text { Momentos } \\
\text { e } \\
\text { periodicida } \\
\text { de }\end{array}$ & Envolvidos & $\begin{array}{l}\text { Atividades } \\
\text { e procedimentos }\end{array}$ \\
\hline prioritários & & & \\
\hline & & & \\
\hline
\end{tabular}

e) Momento 5: operacionalização dos instrumentos e planejamento das ações de monitoramento

Finalmente é chegado o momento de 1) precisar os instrumentos para aferir REVISTA DO DIREITO UNISC, SANTA CRUZ DO SUL No $41 \mid$ p. $89-109 \mid$ NOV - DEZ 2013 
cada impacto priorizado no momento anterior e 2) inserir tais instrumentos no plano de ação do programa. No primeiro caso, especificaremos os indicadores, para os aspectos mais tangíveis ou mensuráveis do programa, e as perguntas orientadoras, para os aspectos de maior dificuldade de aferição (Ascher e Valarelli, 2008, p. 5859). No segundo caso, o plano de monitoramento será apresentado num cronograma de atividades, que deve ser devidamente incorporado na agenda, para evitar sua secundarização e esquecimento. Completemos, então, a tabela do momento anterior com a coluna dos instrumentos, conforme os quadros 9 e 10:

\begin{tabular}{|l|l|l|l|}
\hline \multicolumn{5}{|c|}{ Quadro 9 } \\
Abordagem negocial \\
Momento 5: operacionalização dos instrumentos e planejamento das ações \\
de monitoramento \\
Impactos diretos
\end{tabular}

\section{Quadro 10}

Abordagem negocial

Momento 5: operacionalização dos instrumentos e planejamento das ações de monitoramento 


\begin{tabular}{|l|l|l|l|l|}
\hline \multicolumn{5}{|c|}{ Impactos indiretos } \\
\hline $\begin{array}{l}\text { Impactos } \\
\text { indiretos } \\
\text { prioritários }\end{array}$ & $\begin{array}{l}\text { Momentos e } \\
\text { periodicidade }\end{array}$ & Envolvidos & $\begin{array}{l}\text { Atividades } \\
\text { e } \\
\text { procedimento } \\
\text { s }\end{array}$ & Instrumentos \\
\hline & & & & \\
& & & & \\
\hline
\end{tabular}

Especifiquemos agora, nos quadros 11 e 12, os indicadores para que cada instrumento seja de fato eficaz no processo de monitoramento e avaliação, para o que devem ser atribuíveis, isto é, relativos aos processos deflagrados pelos atores do programa; sensíveis, por aferirem de fato a intensidade das mudanças ocorridas no tempo planejado; viáveis, pela disponibilidade de fontes, custo e esforço; confiáveis, pela qualidade do levantamento de dados; inteligíveis, por conta da transparência da metodologia e comunicáveis, ou melhor, compreensíveis pela sociedade civil (Ascher e Valarelli, 2008, p. 67):

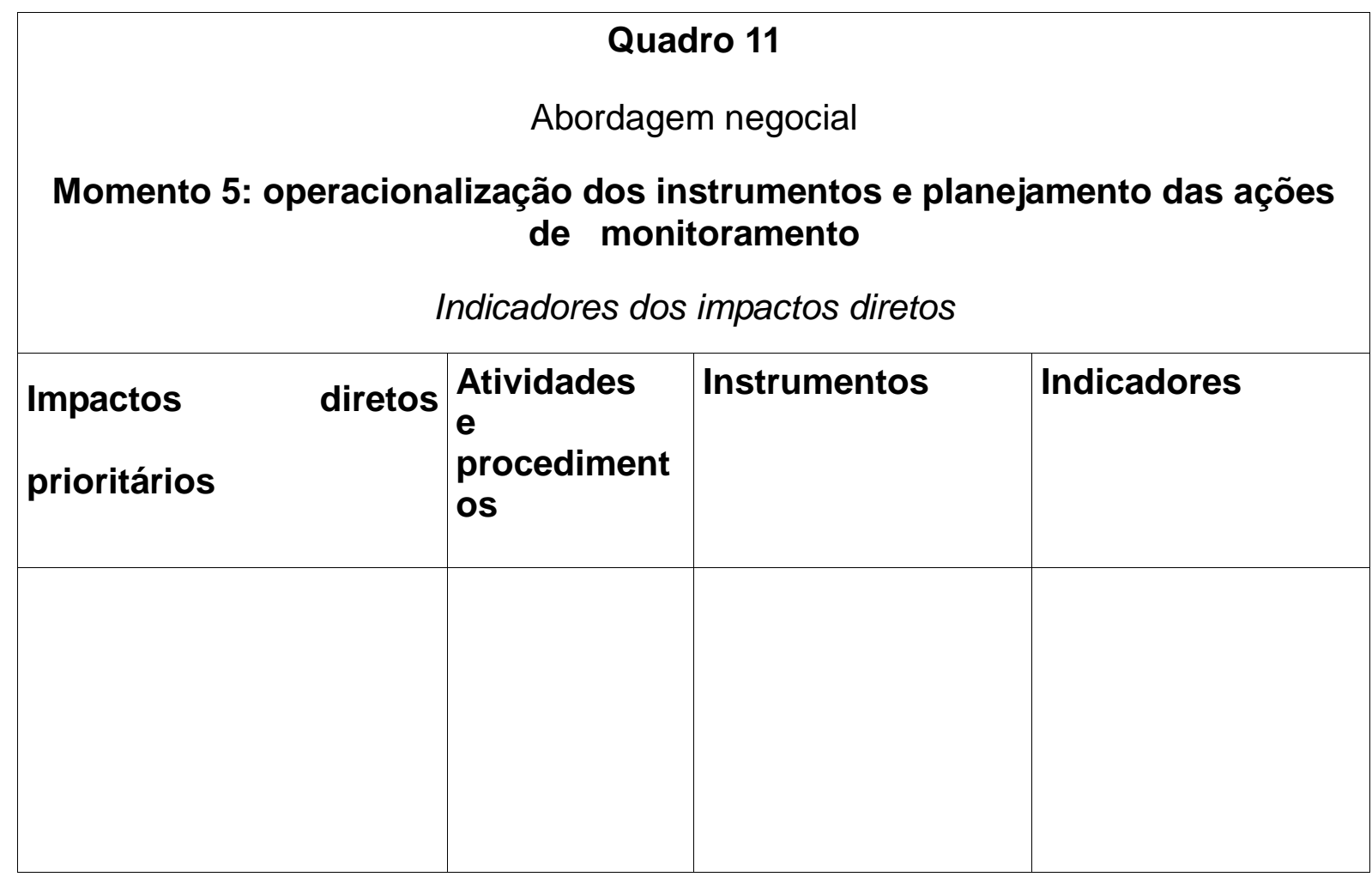




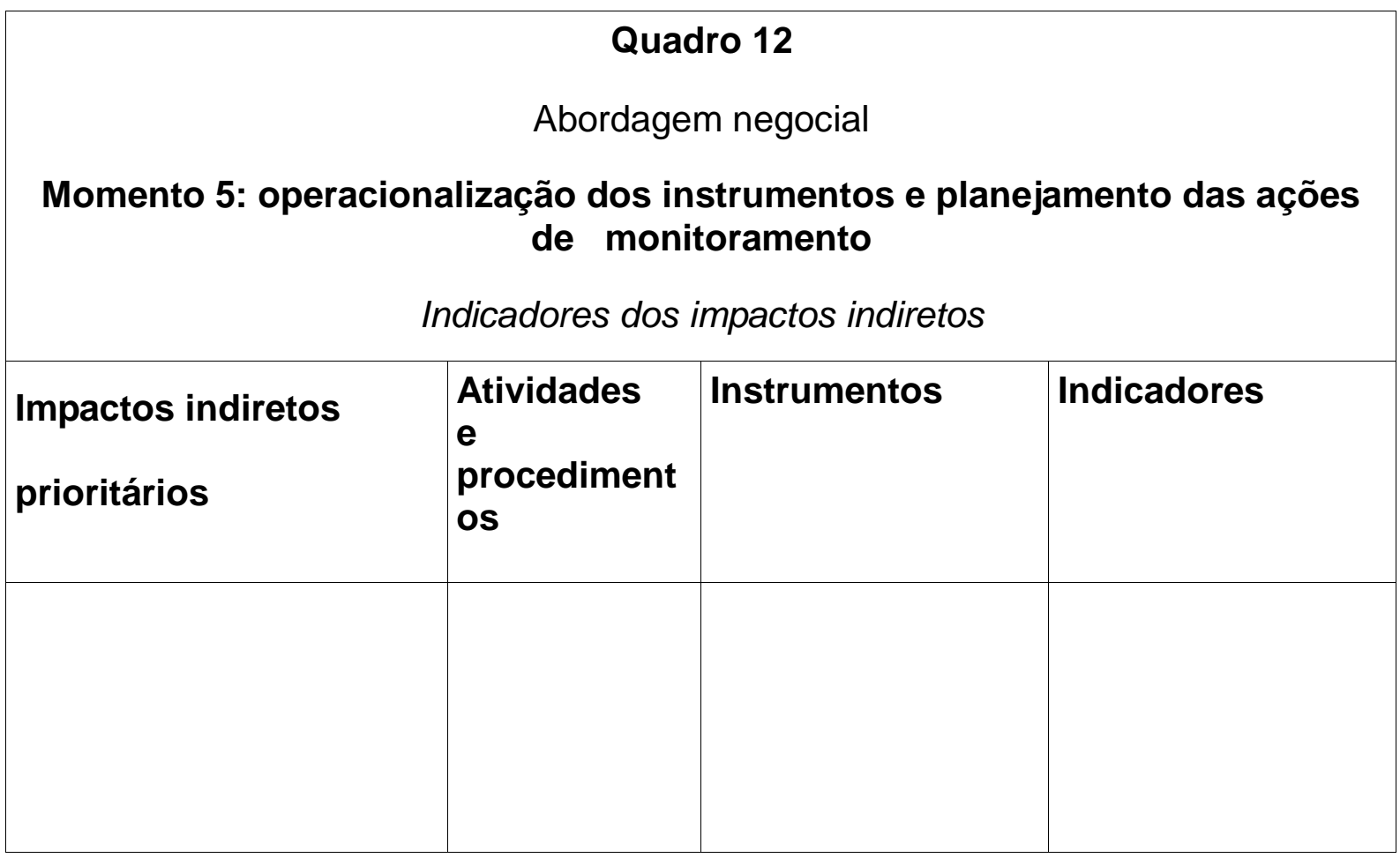

Finalmente, é preciso organizar o monitoramento numa matriz temporal anual, com indicação de atividades, coordenadores das mesmas e os recursos adequados para seu êxito. Esses dados podem alimentar um simples cronograma, como o do quadro 13:

\begin{tabular}{|l|l|l|l|l|l|l|l|l|l|l|l|l|l|l|l|l|}
\hline \multicolumn{10}{|c|}{ Quadro 13 } \\
Cronograma \\
\hline Atividades & $\begin{array}{l}\text { Responsá } \\
\text { veis }\end{array}$ & J & F & M & A & M & J & J & A & S & O & N & D & J & F & $\begin{array}{l}\text { Recurso } \\
\text { S }\end{array}$ \\
\hline & & & & & & & & & & & & & & & & \\
\hline
\end{tabular}

É claro que os mapas e tabelas acima foram montados a título de exemplo. Os mapas e tabelas reais devem ser feitos de modo compartilhado com os diferentes atores do programa, dispostos a aprender com o processo e motivados 
para tomar as decisões necessárias para que o programa seja, ao mesmo tempo, um fator de transformação da realidade social, no sentido de incentivar a prática da cidadania ativa em nosso país, e um fator de mudança do espaço público estatal num ambiente de exercício da razão argumentativa. Além de um processo de compartilhamento negociado de interesses e motivações, o monitoramento é, portanto, uma ferramenta de aprendizagem democrática.

Por isso, o processo de monitoramento deve ser simples e funcional para que esse processo de aprendizagem para a gestão seja enriquecido gradativamente, de preferência a partir da experiência de controle sistemático de poucos impactos priorizados. De suma importância é a criação de espaços de reflexão e crítica, com divisão de responsabilidades e tomada coletiva de decisões incidentes no planejamento operacional e metodológico que colocará em cena a próxima gestão do programa (Ascher e Valarelli, 2008, p. 74-75).

\section{Considerações finais}

A partir da constatação do atual estágio de insulamento burocrático das políticas públicas nacionais, investigamos sucintamente acima qual o método mais adequado para conduzir sua aproximação com a população brasileira carente de formação política e apoio para o exercício corajoso do controle social, não como consigna abstrata, mas como forma procedimentalizada de participação nos negócios do Estado.

A considerar a configuração político-institucional de nossas políticas sociais (que, apesar de sua vocação de abertura para a sociedade, são fortemente limitadas por uma ossatura burocrática extremamente hierarquizada e fechada), indicamos a abordagem negocial como o modelo mais indicado de monitoramento e avaliação, para, de um lado, favorecer o processo de abertura dos programas públicos e, de outro, catalisar a superação do modelo autoritário por um modelo republicano de gestão e disseminação do controle democrático do Estado.

É certo que, com a finalidade de fomentar a cidadania ativa em nosso país, temos um débito para com as conquistas normativas condensadas na Constituição de 88. O Poder Executivo, nos quatro entes federativos, não pode governar sozinho; 
deve cumprir com urgência a promessa de participação popular em nossa ordem política. Mas, para isso, deve ampliar seu alcance e abrir suas estruturas, dialogar com a sociedade civil e colocar em prática um plano partilhado de governança que permita aos diversos atores envolvidos e à opinião pública nacional e internacional saber se sua missão está sendo efetivamente cumprida.

Não há democracia sem procedimentos claros de cogestão entre sociedade e governos no planejamento, execução, monitoramento e avaliação das ações públicas. Também não há república sem a partilha do poder de governar. Como nos alertou Bauman (2000, p. 15) "a liberdade individual só pode ser produto do trabalho coletivo". É, pois, razoável pensar que é o campo das políticas públicas o caminho mais eficaz de mudança do conceito de política.

\section{REFERÊNCIAS}

ASSA-ARZABE, P. H. Dimensão jurídica das políticas públicas in BUCCI, M. P. D. (org). Políticas Públicas: reflexões sobre o conceito jurídico. Rio de Janeiro: Saraiva, 2006, p. 51-74.

ASCHER, P; VALARELLI, L. L. Monitoramento de impacto: uma proposta metodológica. Brasília: MMA, 2008.

BAUMAN, Z. Z. Em busca da política. Rio de Janeiro: Zahar, 2000.

BRASIL, Constituição da República Federativa, promulgada em 05 de outubro de 1988.

CANOTILHO, J. J. G. Direito constitucional. Coimbra: Almedina, 1992.

DYE, Thomas D. Understanding Public Policy. Englewood Cliffs, N.J.: PrenticeHall. 1984.

EASTON, D. A Framework for Political Analysis. Englewood Cliffs: Prentice Hall. 1965.

HABERMAS, J. Mudança estrutural da esfera pública: investigações quanto a uma categoria da sociedade burguesa. Rio de Janeiro: Tempo Brasileiro, 1984.

Direito e democracia: entre facticidade e validade. Rio de Janeiro: Tempo Brasileiro, 1997.

LASWELL, H.D. Politics: Who Gets What, When, How. Cleveland: Meridian Books, 1936/1958. 
LINDBLOM, Charles E. "The Science of Muddling Through", Public Administration Review 19: 78-88. 1959. 526. 1979.

"Still Muddling, Not Yet Through", Public Administation Review 39: 517-

LOWI, Theodor. "American Business, Public Policy, Case Studies and Political Theory", World Politics, 16: 677-715. 1964.

. "Four Systems of Policy, Politics, and Choice". Public Administration

Review, 32: 298-310. 1972.

MEAD, L. M. "Public Policy: Vision, Potential, Limits", Policy Currents, Fevereiro: 14. 1995.

OLSON, Mancur. The Logic of Collective Action. Cambridge, Mass.: Harvard University Press: 1965.

PESSOA, R. S. Neoconstitucionalismo, política e administração pública dilemas a serem enfrentados. In: Revista Interesse Público, ano 8, nº 39, set/out de 2006.

SIMON, Herbert. Comportamento Administrativo. Rio de Janeiro: USAID, 1957.

SOUZA, C. "Políticas Públicas: uma revisão da literatura", Sociologias, Porto Alegre, ano 8, no 16, jul/dez 2006, p. 20-45.

VALARELLI, L. L. A gestão de projetos e a construção e o uso de indicadores. Rio de Janeiro: e-book, 2005. In Construindo Sistemas de Monitoramento e Avaliação. Brasília: MMA, 2006. 